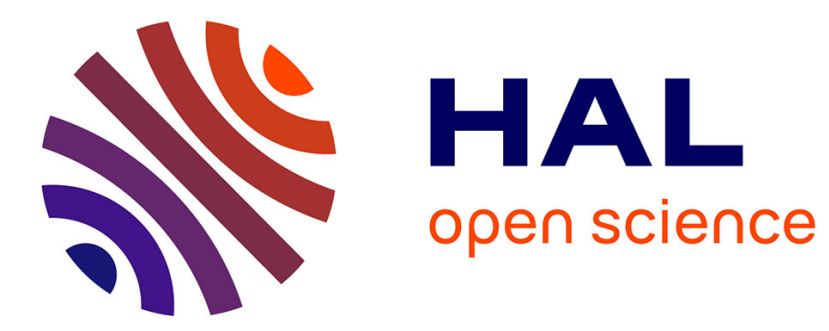

\title{
Critical behaviour of transport coefficients at a structural-ferromagnetic transition
}

\author{
J. Sousa, M. Amado, R. Pinto, J. Moreira, M. Braga, M. Ausloos, J. \\ Leburton, P. Clippe, J. van Hay, P Morin
}

\section{- To cite this version:}

J. Sousa, M. Amado, R. Pinto, J. Moreira, M. Braga, et al.. Critical behaviour of transport coefficients at a structural-ferromagnetic transition. Journal de Physique Colloques, 1979, 40 (C5), pp.C5-42-C543. 10.1051/jphyscol:1979516 . jpa-00218933

\section{HAL Id: jpa-00218933 https://hal.science/jpa-00218933}

Submitted on 1 Jan 1979

HAL is a multi-disciplinary open access archive for the deposit and dissemination of scientific research documents, whether they are published or not. The documents may come from teaching and research institutions in France or abroad, or from public or private research centers.
L'archive ouverte pluridisciplinaire HAL, est destinée au dépôt et à la diffusion de documents scientifiques de niveau recherche, publiés ou non, émanant des établissements d'enseignement et de recherche français ou étrangers, des laboratoires publics ou privés. 


\title{
Critical behaviour of transport coefficients at a structural-ferromagnetic transition $(*)$
}

\author{
J. B. Sousa, M. M. Amado, R. P. Pinto, J. M. Moreira, M. E. Braga \\ Univ. Porto, Portugal $\left({ }^{a}\right)$ \\ M. Ausloos, J. P. Leburton, P. Clippe, J. C. van Hay \\ Univ. Liège, Belgium $\left(^{b}\right)$ \\ and P. Morin \\ Lab. Louis-Néel, CNRS, Grenoble, France
}

\begin{abstract}
Résumé. - On rapporte des mesures précises de la résistivité électrique, du pouvoir thermoélectrique, et de la conductivité thermique de $\mathrm{TbZn}$. La dérivée des coefficients par rapport à la température est examinée. Le comportement critique est expliqué par la diffusion électronique sur les fluctuations de spin corrélées et par la présence de domaines magnétiques et structuraux.
\end{abstract}

\begin{abstract}
Accurate measurements of the electrical resistivity, the thermoelectric power and the thermal conductivity of $\mathrm{TbZn}$ are reported at the ferromagnetic-structural transition. The temperature derivative of the coefficients is examined. The critical behaviours are understood in terms of conduction electron scattering on spin correlated fluctuations and the presence of structural and magnetic domains.
\end{abstract}

A detailed characterization of the static properties of the equiatomic $\mathrm{Cs}-\mathrm{Cl}$ compounds of the rare earth metals with $\mathrm{Zn}$ is available [1]. Here we extend our knowledge of such systems to the case of transport properties, using a monocrystalline sample of $T \mathrm{bZn}$. It has a ferro-paramagnetic transition at $T_{\mathrm{c}}=200 \mathrm{~K}$, with an apparently simultaneous cubic to tetragonal transition; the easy magnetic direction occurs along a quaternary axis. At $T_{\mathrm{R}}=63 \mathrm{~K}$, the lattice distortion practically disappears and the easy magnetic direction rotates to a binary axis [1].

Figure 1 shows the general behaviour of the electrical resistivity $(\rho)$ and its temperature derivative $\mathrm{d} \rho / \mathrm{d} T$ along a quaternary axis. The data have been normalized by a factor $\rho_{\mathrm{c}}=\rho\left(T_{\mathrm{c}}\right)$. The phase transitions in $\mathrm{TbZn}$ are clearly revealed in the $\mathrm{d} \rho / \mathrm{d} T$ curve, which is remarkably similar to that of the specific heat $(C)$ (inset of figure 1; from [1]). The ferroparamagnetic transition induces a peak in $\mathrm{d} \rho / \mathrm{d} T$, followed by an extended tail in the paramagnetic phase due to short range order. The transition at $T_{\mathrm{R}}$ is accompanied by a latent heat and marked by a very high and narrow peak, in a manner characteristic of 1st-order transitions [2]. The resistivity is practically discontinuous at $T_{\mathrm{R}}(\Delta \rho / \rho \simeq 5 \%)$, whereas $\mathrm{d} \rho / \mathrm{d} T$ changes by $20 \%$. A qualitatively similar mismatch occurs also in $C$ at $T_{\mathrm{R}}$ (see inset).

$\left(^{*}\right)$ Work supported by INIC, Portugal $\left({ }^{a}\right)$, ESIS, Belgium $\left({ }^{b}\right)$, NATO Research Grant $1481\left(^{a}\right)$, $\left({ }^{b}\right)$.

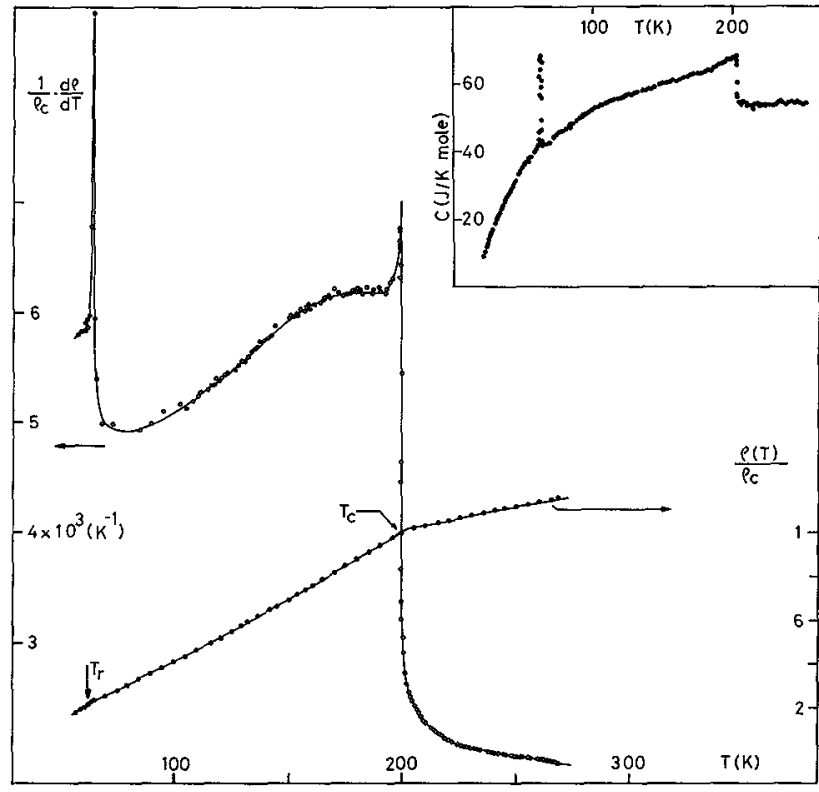

Fig. 1. - Normalized $c$-axis resistivity and temperature derivative of single crystal $\mathrm{TbZn}$; inset : specific heat from [1].

The thermoelectric power $(S)$ has been measured from 90 to $300 \mathrm{~K}$. The temperature gradient was along a quaternary axis. Figure 2 shows that $S$ is negative. The critical temperature $T_{\mathrm{c}}$, as derived from $\mathrm{d} \rho / \mathrm{d} T$ measurements is indicated. The pronounced increase in $S$ below $T_{\mathrm{c}}$ is indicative of a $H_{\text {sd }}$ conduc- 


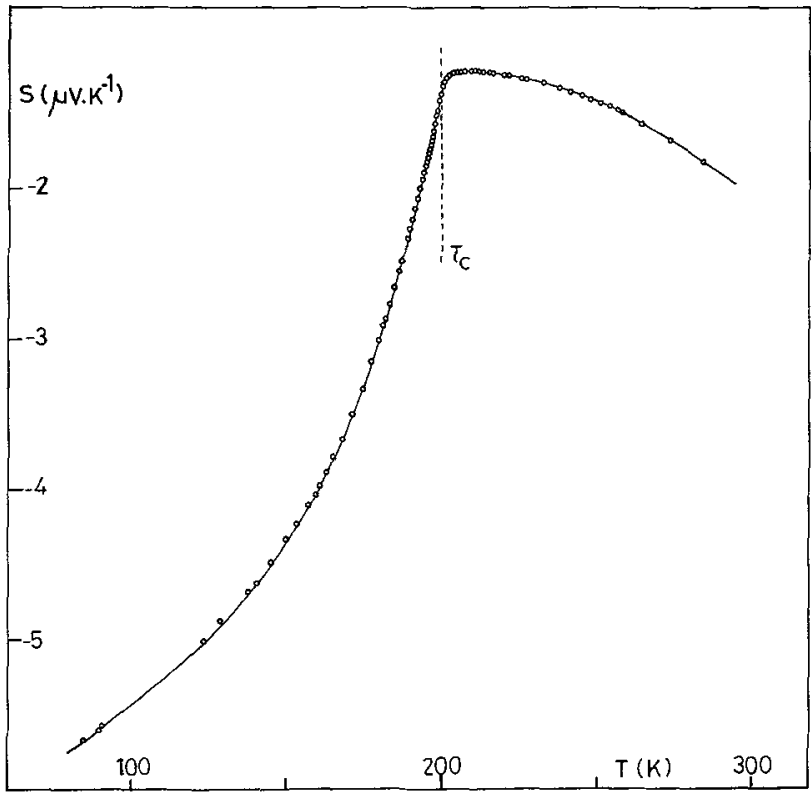

Fig. 2. $-c$-axis thermoelectric power of single crystal $\mathrm{TbZn}$.

tion electron-localized spin interaction [3]. This behaviour is similar to that observed in pure $\mathrm{Tb}$ along a basal axis [4]. The data for $S$ above $T_{\mathrm{c}}$ practically extrapolate through the origin, whereas its slope is rather small and negative. This indicates a holedominated thermopower, in contrast to pure $\mathrm{Tb}$, where the slope above $T_{\mathrm{c}}$ is positive. Figure 3 shows the derivative $\mathrm{d} S / \mathrm{d} T$ for $\mathrm{TbZn}$. It is remarkable that $\mathrm{d} S / \mathrm{d} T$ presents a characteristic $\lambda$-shape anomaly, with a sharp peak at $T_{\mathrm{c}}$, reminiscent of that found in $\mathrm{d} \rho / \mathrm{d} T$ near $T_{\mathrm{c}}$. Important differences are apparent at lower temperatures. Whereas $\mathrm{d} S / \mathrm{d} T$ decreases smoothly and monotonically with $T, \mathrm{~d} \rho / \mathrm{d} T$ exhibits anomalously high values and a complex behaviour. Any reasonable theory must explain why such effects are so exhuberantly present in $\mathrm{d} \rho / \mathrm{d} T$ and not in $\mathrm{d} S / \mathrm{d} T$ [5].

We have also measured the thermal conductivity $(K)$, using a novel experimental approach described

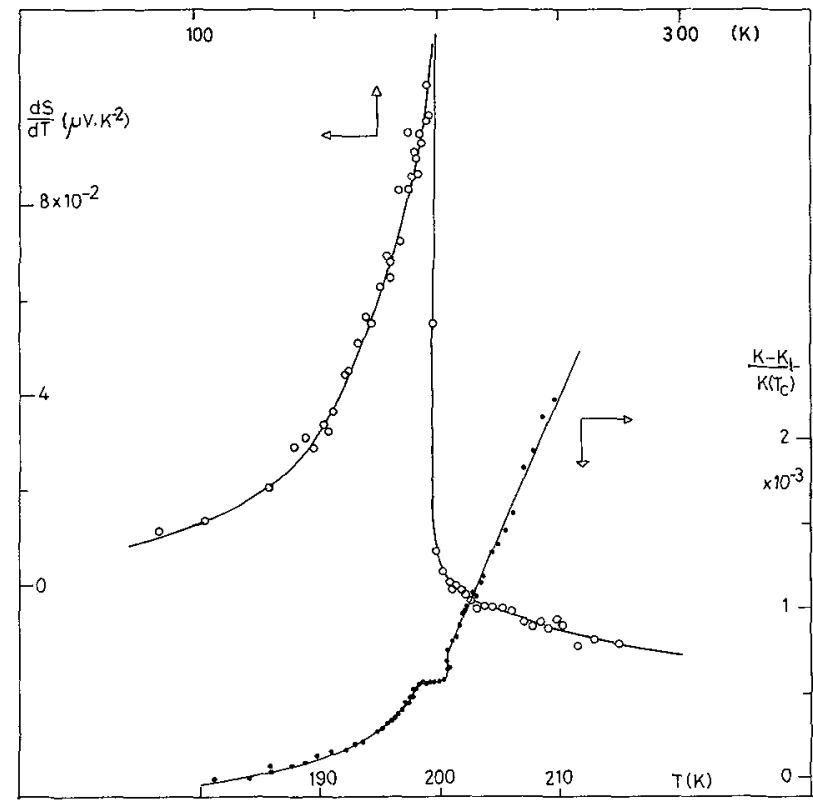

Fig. 3. - c-axis temperature derivative of thermoelectric power and normalized thermal conductivity of $\mathrm{TbZn}$.

elsewhere [6]. This enables the small changes of $K$ near $T_{\mathrm{c}}$ to be accurately measured (figure 3 ). For convenience, a linear background has been previously extracted, so as to reveal more clearly the changes in $K$ near $T_{\mathrm{c}}$. The main features are a localized depression in $K$ near $T_{\mathrm{c}}$ and a pronounced increase in the slope $\mathrm{d} K / \mathrm{d} T$ when the sample enters the paramagnetic state. The depression in $K$ is consistent with the expected reduction in the mean free path of the long wavelength phonons caused by the critical fluctuations [7]. The increase in $\mathrm{d} K / \mathrm{d} T$ can be qualitatively understood in terms of the electronic contribution to $K$ [8].

Finally the existence of time-dependent effects below $T_{\mathrm{c}}$ is most probably due to magnetic and structural domains. The influence of such domains on transport properties is being worked out theoretically [5]. Technical assistance of $J$. Bessa is gratefully acknowledged.

\section{References}

[1] Morin, P., Doctoral Thesis, C.N.R.S. 9323 (1975).

[2] Marques, M. C., Sousa, J. B., Pinheiro, M. F., Braga, M. E., Script. Metal. 11 (1977) 197.

[3] Kasuya, T., Prog. Theor. Phys. 22 (1959) 227.

[4] Sill, L. R., Legvold, S., Phys. Rev. 137 (1965) A-1139.

[5] Leburton, J. P., Ausloos, M. and Amado, M. M. et al. (Unpublished).

[6] Sousa, J. B., Pinto, R. S., Amado, M. M., Ausloos, M., Huxin, D., Portug. Phys. Conf. 1978 (to appear in Portug. Phys.).

[7] KaWASAKI, K., Prog. Theor. Phys. 29 (1963) 801.

[8] Neldis, W. J., Legvold, S., Phys. Rev. 180 (1969) 582. 